Bentham open

RESEARCH ARTICLE

\title{
Predicted Values for Spirometry may Underestimate Long-Standing Asthma Severity
}

\author{
Bruno Sposato* \\ Unit of Pneumology, "Misericordia” Hospital, Grosseto, Italy
}

Received: June 22, 2016

Revised: November 14, 2016

Accepted: November 14, 2016

\begin{abstract}
:
Background:

Asthma may show an accelerated lung function decline. Asthmatics, although having $\mathrm{FEV}_{1}$ and $\mathrm{FEV}_{1} / \mathrm{VC}$ (and z-scores) higher than the lower limit of normality, may show a significant $\mathrm{FEV}_{1}$ decline when compared to previous measurements. We assessed how many asymptomatic long-standing asthmatics (LSA) with normal lung function showed a significant $\mathrm{FEV}_{1}$ decline when an older $\mathrm{FEV}_{1}$ was taken as reference point.
\end{abstract}

\section{Methods:}

46 well-controlled LSA (age: 48.8 $\pm 12.1 ; 23$ females) with normal $\mathrm{FEV}_{1}$ and $\mathrm{FEV}_{1} / \mathrm{VC}$ according to GLI2012 references $(\mathrm{FEV}$ : 94.8 $\pm 10.1 \%$, z-score:- $0.38 \pm 0.79 ; \mathrm{FEV}_{1} / \mathrm{VC}$ : $79.3 \pm 5.2$, z-score:-0.15 \pm 0.77$)$ were selected. We considered $\mathrm{FEV}_{1}$ decline, calculated by comparing the latest value to one at least five years older or to the highest predicted value measured at 21 years for females and 23 for males. $\mathrm{A} \mathrm{FEV}_{1}$ decline $>15 \%$ or $30 \mathrm{ml} /$ years was regarded as pathological.

\section{Results:}

When comparing the latest $\mathrm{FEV}_{1}$ to an at least 5-year-older one (mean $8.1 \pm 1.4$ years between 2 measurements), 14 subjects (30.4\%) showed a FEV ${ }_{1}$ decline $<5 \%$ (mean: $-2.2 \pm 2.6 \%$ ), 19 (41.3\%) had a FEV $5-15 \%$ change (mean: $-9.2 \pm 2.5 \%$ ) and $13(28.3 \%)$ a FEV 1 decrease $>15 \%$ (mean: $-18.3 \pm 2.4$ ). Subjects with a $\mathrm{FEV}_{1}$ decline $>30 \mathrm{ml} /$ year were $28(60.8 \%)$. When using the highest predicted $\mathrm{FEV}_{1}$ as reference point and declines were corrected by subtracting the physiological decrease, $6(13 \%)$ patients showed a FEV 1 decline higher than $15 \%$, whereas asthmatics with a $\mathrm{FEV}_{1}$ loss $>30 \mathrm{ml} /$ year were 17 (37\%).

\section{Conclusion:}

$\mathrm{FEV}_{1}$ decline calculation may show how severe asthma actually is, avoiding a bronchial obstruction underestimation and a possible under-treatment in lots of apparent "well-controlled" LSA with GLI2012-normal-range lung function values.

Keywords: Asthma, Lung function, Reference values, Spirometry, $\mathrm{FEV}_{1}$ decline.

\section{INTRODUCTION}

According to guidelines, symptom severity, short-acting bronchodilator usage, disease exacerbations in the previous month and pulmonary function level set asthma treatment. Especially when spirometry values are below the predicted value normal limit, patients should be treated regularly and therapy level might be increased when necessary. This concerns also asymptomatic patients with an airway obstruction to be considered as poorly controlled. In addition, a significant peak expiratory flow (PEF) reduction $>20 \%$ and/or a $\mathrm{FEV}_{1}$ decrease $\geq 12 \%$, when compared to measurements performed days/weeks/months earlier, indicate significant lung function/asthma worsening and therefore

\footnotetext{
* Address correspondence to this author at the U.O. Pneumologia, Azienda Ospedaliera "Misericordia", Via Senese 161; 58100 GROSSETO, Italy; Tel: +390564485454; Fax: +390564485450; E-mail: bsposat@tin.it
} 
a treatment step-up [1,2]. However, asthma guidelines [1] do not suggest using slower/not easily detectable $\mathrm{FEV}_{1}$ long-term decline to establish if lung function (and therefore asthma) worsened after several years despite a good asthma control. In fact, if $\mathrm{FEV}_{1}$, checked after inhaling bronchodilator, is compared to previous measurements (effected at least 5 years earlier) [3] and if $\mathrm{FEV}_{1}$ change $>30 \mathrm{ml} / \mathrm{year}$ or $\geq 15 \%$ is found, such decrease should be regarded as pathological (airway obstruction) [2, 3]. Significant long term $\mathrm{FEV}_{1}$ reduction/decline measurements can be considered an indirect method for assessing bronchial wall thickening and disease progression [3]. However, $\mathrm{FEV}_{1}$ changes may be mistaken for those occurring among repeated measurements $[2,4]$. Therefore, we should evaluate them by comparing such FEV ${ }_{1}$ changes with an at least five-year-old measurement, in order not to confuse deterioration due to remodeling with the above said lung function fluctuations [3]. We know that "declining" asthmatics, whose significant irreversible airways obstruction develops over time, are approximately $20-35 \%$ of asthmatic patients. This may also regard asthmatics with pulmonary function within the predicted normal range if their latest "normal" lung function is compared with an at least five-year-old higher measurement. This apparent "normality" is due to a yearly predicted reference reduction that may hide a possible lung function decline due to asthma, leading to an underestimation of airflow limitation $[3,5]$. In fact, pulmonary function might be within the predicted normal range despite a significant lung function decline. The absence of symptoms in such patients might lead to an undervaluation of asthma severity [3]. This is why it may be important to compare the latest spirometry with at least a five-year-old one when managing asthma. Nowadays, we do not know how many "well controlled" long acting asthmatics, with apparent lung function normality, can actually show an accelerated $\mathrm{FEV}_{1}$ decline, leading to an evaluation bias.

Recently, the Global Lungs Initiative (GLI) 2012 has made available spirometric prediction equations for the 3-95 age range, including appropriate age-dependent lower limits of normal [6 - 8]. Adopting GLI 2012 prediction equations will have little effect on the detection of obstructive patterns when compared to previous NHANES and ECSC/ERS equations.

On the basis of these considerations, objective of this study was to establish the number of subjects that showed a significant $\mathrm{FEV}_{1}$ decline in a group of asthmatics with normal lung function in the latest assessment, according to GLI2012 references. Furthermore, we wanted to know the number of subjects with significant $\mathrm{FEV}_{1}$ changes in time, taking as reference points the highest predicted values measured at 21 years for females and 23 for males, (when these references are higher) in order to calculate such decline.

\section{PATIENTS AND METHODS}

We selected and retrospectively analyzed 46 consecutive long-standing asthmatics from our outpatient database (mean age: $48.8 \pm 12.1 ; 23$ females, 4 current smokers; 40 sensitized at least to one aero-allergen). They all had normal lung function, in particular $\mathrm{FEV}_{1}$ and $\mathrm{FEV}_{1} / \mathrm{VC}$ greater than the LLN, with their z-score between -1.5 and 1.5 , calculated by using GLI equations) [6 - 8] $\left(\mathrm{FEV}_{1}: 94.8 \pm 10.1 \%\right.$, z-score: $-0.38 \pm 0.79$; $\mathrm{FEV}_{1} / \mathrm{VC}: 79.3 \pm 5.2$, z-score: $-0.15 \pm 0.77)$. They all had also a clinical stable disease at least in the previous 6 months with an Asthma Control Test (ACT) score $>20$ at the time of the latest assessment. Pulmonary function data, aero-allergenic sensitization to prick tests, exacerbation rates (defined by the use of systemic corticosteroid and/or emergency room accesses), ACT score, treatment and adherence, were taken from the medical record of each patient. For the purpose of this study, all patients' $\mathrm{FEV}_{1}$ and $\mathrm{FEV}_{1} / \mathrm{VC}$ measurements with their z-scores - measured after bronchodilator (Salbutamol) at the start and at the end of at least a 5-year period of time - were considered. Previous $\mathrm{FEV}_{1}$ and $\mathrm{FEV}_{1} / \mathrm{VC}$ values (and their $\mathrm{z}$-scores) measured at least 5 years before the latest measurement and the highest predicted $\mathrm{FEV}_{1}$ values (obtained at 21/23 years for females and males respectively) were considered as reference points to calculate $\mathrm{FEV}_{1}$ decline for each patient. Therefore, absolute $(\mathrm{ml})$ and percentage changes between the latest and the oldest $\mathrm{FEV}_{1}$ and between the latest $\mathrm{FEV}_{1}$ value and the highest predicted $\mathrm{FEV}_{1}$ values, were taken into account.

Annual $\mathrm{FEV}_{1}$ changes obtained for each patient were expressed in $\mathrm{ml} / \mathrm{year}$. When the oldest $\mathrm{FEV}_{1}$ value was used as reference point, $\mathrm{FEV}_{1}$ change was calculated by subtracting the latest measured value from the oldest $\mathrm{FEV} \mathrm{V}_{1,}\left[\left(\mathrm{FEV}_{1 \text { previous }}\right.\right.$ $-\mathrm{FEV}_{1 \text { latest }} /$ years] and then subdivided by the years separating the two measurements. When the reference point was the highest $\mathrm{FEV}_{1}$ predicted value, the variation was calculated by subtracting the latest measured value from the highest 
$\mathrm{FEV}_{1}$ predicted value, $\left[\left(\mathrm{FEV}_{1 \text { highest predicted }}-\mathrm{FEV}_{1 \text { latest }}\right) /\right.$ years $]$, when it is usually higher. This value was then subdivided by the years separating the two measurements. Percentage change was calculated by subtracting the previous absolute measurement or the highest predicted values (expressed in $\mathrm{ml}$ ) from the latest measurement and then divided by the previous or the highest predicted measurements $* 100$ : $\left[\left(\mathrm{FEV}_{1 \text { previous }}-\mathrm{FEV}_{1 \text { latest }}\right) / \mathrm{FEV}_{1 \text { old }}\right]^{*} 100$ and $\left[\left(\mathrm{FEV}_{1 \text { highest predicted }}-\right.\right.$

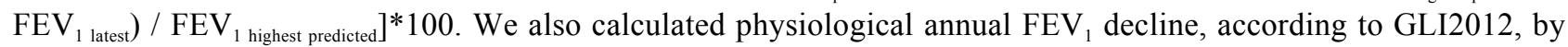
subtracting the predicted value of the latest measurement from the highest predicted $\mathrm{FEV}_{1}$ value, and then by subdividing by the years elapsed between the two measurements: $\left[\left(\mathrm{FEV}_{1 \text { highest predicted }}-\mathrm{FEV}_{1 \text { latest predicted }}\right) /\right.$ years $]$. The physiological change percentage was calculated by using the following formula: $\left[\left(\mathrm{FEV}_{1 \text { highest predicted }}-\mathrm{FEV}_{1 \text { latest predicted }}\right) /\right.$ $\left.\mathrm{FEV}_{1 \text { highest predicted }}\right] * 100$.

Arbitrarily, on the basis of a $\mathrm{FEV}_{1}$ decrease $<5 \%$, or $5-15 \%$ or $>15 \%$, obtained between the oldest and the latest measurements, patients were subdivided into three groups, Also an annual $\mathrm{FEV}_{1}$ change $<30,30-60$ and $>60 \mathrm{ml} / \mathrm{year}$ was used to calculate the prevalence of subjects with different $\mathrm{FEV}_{1}$ declines expressed in $\mathrm{ml} /$ year. When the reference point was the highest predicted $\mathrm{FEV}_{1}$, the percentage changes from the latest measurement were higher as the years separating the two measurements were more numerous, above all in subjects of medium/old age. Therefore, to correct the bias, $\mathrm{FEV}_{1} \%$ decline was calculated by using the above mentioned formulas, but subtracting physiological $\mathrm{FEV}_{1}$ decline measured between the two normal predicted values (highest predicted $\mathrm{FEV}_{1}$ and predicted value of the latest measured $\left.\mathrm{FEV}_{1}\right)$. For this reason, the corrected formula was: $\left[\left(\mathrm{FEV}_{1 \text { highest predicted }}-\mathrm{FEV}_{1 \text { latest }}\right)-\left(\mathrm{FEV}_{1 \text { highest predicted }}-\mathrm{FEV} \mathrm{l}_{\text {latest }}\right.\right.$ predicted $\left.) / \mathrm{FEV}_{1 \text { highest predicted }}\right]^{*} 100$. All functional data of formulas were considered in liters. A FEV $\mathrm{F}_{1}$ decrease in time, greater than $15 \%$ or $30 \mathrm{ml} /$ years for each patient, compared to one of their previous highest $\mathrm{FEV}_{1}$ measurements and to their highest predicted value (having removed physiological $\mathrm{FEV}_{1}$ decline when using cut-off percentage) was considered expressive of pathological long term $\mathrm{FEV}_{1}$ decline. All subjects had been treated with low/medium doses of inhaled corticosteroids, sometimes associated to long-acting bronchodilators and montelukast. The asthma diagnosis was made

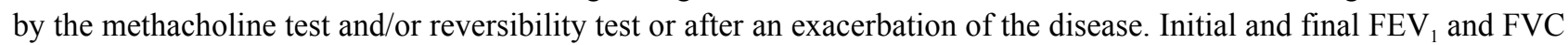
measurements should be $<12 \%$ increase after salbutamol.

The retrospective use of data for this study was approved by the local ethical Committee (Prot. 178/25-09-2012).

\section{STATISTICAL ANALYSIS}

Unpaired and paired ANOVA tests were used, when appropriate, to compare functional parameters among different groups. A $\chi^{2}$ test was used to compare the prevalence of subjects with different $\mathrm{FEV}_{1}$ declines.

\section{RESULTS}

In Table 1 are summarized spirometric measurements obtained in the three groups with low $(<5 \%)$, medium (5-15\%) and high (>15\%) $\mathrm{FEV}_{1}$ decline. Obviously, in groups with a greater lung function dceline, the oldest and latest parameters were different (Table 1). When we considered the highest predicted or older values as reference to calculate their $\mathrm{FEV}_{1} \%$ and $\mathrm{z}$-score, the first and the last measurements were similar in the group with a $5 \% \mathrm{FEV}_{1}$ long-term change, but not in the groups with $5-10 \%$ and $>15 \%$ decrease (Table 1).

Table 1. Mean values of lung function measured in the 3 groups of long-standing asthmatics with different $F E V_{1}$ decline.

\begin{tabular}{|c|c|c|c|c|c|c|c|c|c|}
\hline & \multicolumn{3}{|c|}{$\begin{array}{c}\text { Asthmatics with } \mathrm{FEV}_{1} \text { long-term change } \\
\leq 5 \% \\
(14 \text { subjects })\end{array}$} & \multicolumn{3}{|c|}{$\begin{array}{c}\text { Asthmatics with } \mathrm{FEV}_{1} \text { long-term change } \\
\text { between } 5 \text { and } 15 \% \\
\text { (19 subjects) }\end{array}$} & \multicolumn{3}{|c|}{$\begin{array}{c}\text { Asthmatics with } \mathrm{FEV}_{1} \text { long-term change } \\
>15 \% \\
(13 \text { subjects })\end{array}$} \\
\hline & $\begin{array}{c}\text { Previous } \\
\text { measurement }\end{array}$ & $\begin{array}{c}\text { Latest } \\
\text { measurement }\end{array}$ & $\mathbf{p}$ & $\begin{array}{c}\text { Previous } \\
\text { measurement }\end{array}$ & $\begin{array}{c}\text { Latest } \\
\text { measurement }\end{array}$ & $\mathbf{p}$ & $\begin{array}{c}\text { Previous } \\
\text { measurement }\end{array}$ & $\begin{array}{c}\text { Latest } \\
\text { measurement }\end{array}$ & $\mathbf{p}$ \\
\hline $\mathrm{FEV}_{1} \mathrm{~L}$ & $3.36 \pm 0.88$ & $3.3 \pm 0.9$ & 0.412 & $3.18 \pm 0.72$ & $2.9 \pm 0.7$ & $<0.01$ & $3.55 \pm 0.7$ & $2.91 \pm 0.62$ & $<0.001$ \\
\hline FEV $_{1 \%}$ & $96.74 \pm 9.34$ & $101.17 \pm 10.75$ & $<0.001$ & $95.34 \pm 9.58$ & $92.1 \pm 9.01$ & $<0.001$ & $105.1 \pm 9.34^{*}$ & $91.26 \pm 8.15^{\circ}$ & $<0.001$ \\
\hline z-score FEV ${ }_{1}$ & $-0.24 \pm 0.76$ & $0.11 \pm 0.87$ & $<0.001$ & $-0.36 \pm 0.78$ & $-0.58 \pm 0.71$ & $<0.001$ & $0.42 \pm 0.74$ & $-0.64 \pm 0.6$ & $<0.001$ \\
\hline $\mathrm{FEV}_{1} / \mathrm{VC}$ & $81.14 \pm 5.99$ & $80.35 \pm 5.78$ & 0.458 & $81.73 \pm 5.3$ & $80.21 \pm 5.28$ & 0.076 & $81.6 \pm 4.85$ & $76.92 \pm 3.79$ & $<0.001$ \\
\hline \begin{tabular}{|l} 
z-score \\
FEV $/$ VC
\end{tabular} & $-0.23 \pm 0.78$ & $-0.06 \pm 0.79$ & 0.344 & $0.01 \pm 0.72$ & $-0.01 \pm 0.78$ & 0.870 & $0.06 \pm 0.77$ & $-0.46 \pm 0.70$ & 0.002 \\
\hline
\end{tabular}




\begin{tabular}{|c|c|c|c|c|c|c|c|c|c|}
\hline & \multicolumn{3}{|c|}{$\begin{array}{c}\text { Asthmatics with } \text { FEV }_{1} \text { long-term change } \\
\leq 5 \% \\
(14 \text { subjects })\end{array}$} & \multicolumn{3}{|c|}{$\begin{array}{c}\text { Asthmatics with } \mathrm{FEV}_{1} \text { long-term change } \\
\text { between } 5 \text { and } 15 \% \\
(19 \text { subjects })\end{array}$} & \multicolumn{3}{|c|}{$\begin{array}{c}\text { Asthmatics with } \text { FEV }_{1} \text { long-term change } \\
>15 \% \\
(13 \text { subjects })\end{array}$} \\
\hline & $\begin{array}{c}\text { Previous } \\
\text { measurement }\end{array}$ & $\begin{array}{c}\text { Latest } \\
\text { measurement }\end{array}$ & $\mathbf{p}$ & $\begin{array}{c}\text { Previous } \\
\text { measurement }\end{array}$ & $\begin{array}{c}\text { Latest } \\
\text { measurement }\end{array}$ & $\mathbf{p}$ & $\begin{array}{c}\text { Previous } \\
\text { measurement }\end{array}$ & $\begin{array}{c}\text { Latest } \\
\text { measurement }\end{array}$ & $\mathbf{p}$ \\
\hline $\begin{array}{l}F E V_{1} \% \\
(\text { of the highest } \\
\text { predicted } \\
\text { value) }\end{array}$ & $85.85 \pm 13.55$ & $84.2 \pm 15$ & 0.015 & $84.6 \pm 9.6$ & $74 \pm 19.6$ & 0.006 & $90.2 \pm 11.9$ & $73.5 \pm 10.1$ & $<0.001$ \\
\hline $\begin{array}{l}\text { z-score FEV } \\
\text { (of the highest } \\
\text { predicted } \\
\text { value) }\end{array}$ & $-1.19 \pm 1.14$ & $-1.33 \pm 1.26$ & 0.017 & $-1.25 \pm 0.87$ & $-1.91 \pm 0.79$ & $<0.001$ & $-0,83 \pm 1.01$ & $-2,25 \pm 0,85$ & $<0.001$ \\
\hline $\begin{array}{l}\text { FEV } \% \\
\text { (of the previous } \\
\text { value) }\end{array}$ & 100 & $97.8 \pm 2.68$ & 0.009 & 100 & $90.7 \pm 2.52$ & $<0.001$ & 100 & $81.85 \pm 2.47^{\#}$ & $<0.001$ \\
\hline $\begin{array}{l}\text { z-score FEV } \\
\text { (of the previous } \\
\text { value) }\end{array}$ & 0 & $-0.14 \pm 0.20$ & 0.021 & 0 & $-0.7 \pm 0.18$ & $<0.001$ & 0 & $-1.41 \pm 0.25^{\#}$ & $<0.001$ \\
\hline
\end{tabular}

$\mathrm{FEV}_{1} \%$ of the highest predicted values: the highest predicted $\mathrm{FEV}_{1}$ obtained at 21 years for females and 23 years for males was used as reference point to calculate the percentage value of the previous $\left(\mathrm{FEV}_{1 \text { previous }} / \mathrm{FEV}_{\text {lhighest predicted }} * 100\right)$ and the latest $\left(\mathrm{FEV}_{1 \text { latest }} / \mathrm{FEV}_{\text {lhighest predicted }} * 100\right)$ measurements expressed in percentage.

Z-score $\mathrm{FEV}_{1}$ (of the highest predicted values): $\mathrm{Z}$-scores mean values of $\mathrm{FEV}_{1} \%$ (of the highest predicted values).

$\mathrm{FEV}_{1} \%$ of the previous values: the previous $\mathrm{FEV}_{1}$ was used as reference to calculate the percentage value of the previous $\left(\mathrm{FEV}_{1 \text { previous }} / \mathrm{FEV}_{1 \text { previous }} * 100\right)$ and the latest $\left(\mathrm{FEV}_{\text {llatest }} / \mathrm{FEV}_{\text {lprevious }} * 100\right)$ measurements expressed in percentage.

$\mathrm{Z}$-score $\mathrm{FEV}_{1}$ (of the previous predicted values): $\mathrm{z}$-score mean values of $\mathrm{FEV}_{1} \%$ (of the previous values).

${ }^{*}$ comparisons with previous measurements of other groups, $\mathrm{p}=0.017$; ${ }^{\circ}$ comparisons with latest measurements of other groups, $\mathrm{p}=0.012 ;{ }^{*}$ comparisons with latest measurements of other groups, $\mathrm{p}<0.001$.

Paired and unpaired ANOVA tests were used when appropriated.

The time that separated the previous measurements from the latest ones were similar $(8.3 \pm 1.5,7.8 \pm 1.2$ and $8.3 \pm 1.6$ years in subjects with low, medium and high $\mathrm{FEV}_{1}$ decline respectively). Also the time between the highest predicted and latest measurements was similar (Table 2). Obviously, the $\mathrm{FEV}_{1}$ decline from the oldest value, both expressed in $\mathrm{ml} /$ year and percentage was different in the 3 groups (Table 2). Mean values of the highest predicted $\mathrm{FEV}_{1}$ were $3.88 \pm 0.65,3.73 \pm 0.56$ and $3.9 \pm 0.7$ liters in subjects with low, medium and high $F_{E V}$ decline respectively. When the highest predicted $\mathrm{FEV}_{1}$ was used as reference point, $\mathrm{FEV}_{1}$ changes were different among three groups (Table 2). Physiological FEV ${ }_{1}$ decline (calculated by the difference between the highest predicted $\mathrm{FEV}_{1}$ and the predicted value of the latest measurement), both expressed in $\mathrm{ml} /$ year and percentage, were similar in all groups (Table 2).

Table 2. $\mathrm{FEV}_{1}$ decline calculated by subtracting the latest measurement from the previous one or from the highest predicted value. The table shows also the time that separates the latest measurement from the reference points in the 3 groups of longstanding asthmatics with different $\mathrm{FEV}_{1}$ declines.

\begin{tabular}{|c|c|c|c|c|}
\hline & $\begin{array}{c}\text { Asthmatics with } F E V_{1} \text { long- } \\
\text { term change } \leq 5 \% \\
(14 \text { subjects }) \\
\end{array}$ & $\begin{array}{c}\text { Asthmatics with } F E V_{1} \text { long-term } \\
\text { change between } 5 \text { and } 15 \% \\
\text { (19 subjects) } \\
\end{array}$ & $\begin{array}{c}\text { Asthmatics with } \mathrm{FEV}_{1} \\
\text { long-term change }>15 \% \\
(13 \text { subjects }) \\
\end{array}$ & p \\
\hline $\begin{array}{l}\triangle \mathrm{FEV}(\mathrm{ml} / \mathrm{year}) \\
\text { between the previous and the latest } \\
\text { measurements }\end{array}$ & $-7.7 \pm 12.4$ & $-37.1 \pm 9.3$ & $-80.3 \pm 20.3$ & $<0.001$ \\
\hline $\begin{array}{l}\triangle F E V_{1}(\%) \\
\text { between the previous and the latest } \\
\text { measurements }\end{array}$ & $-2.2 \pm 2.6$ & $-9.2 \pm 2.5$ & $-18.3 \pm 2.4$ & $<0.001$ \\
\hline $\begin{array}{l}\text { Time between the previous and the latest } \\
\text { measurements (years) }\end{array}$ & $8.28 \pm 1.54$ & $7.8 \pm 1.22$ & $8.3 \pm 1.6$ & 0.1 \\
\hline $\begin{array}{l}\Delta F E V_{1}(\%) \\
\text { between the highest predicted value and the } \\
\text { latest measurement }\end{array}$ & $-15.8 \pm 15.6$ & $-23 \pm 9.7$ & $-25.9 \pm 11.3$ & 0.025 \\
\hline $\begin{array}{l}\triangle F E V_{1}(\%) \\
\text { between the highest predicted value and the } \\
\text { latest measurement (corrected by physiological } \\
\text { decline) }\end{array}$ & $-1.92 \pm 6.88$ & $-7.03 \pm 6.08$ & $-8.2 \pm 8.5$ & 0.02 \\
\hline
\end{tabular}




\begin{tabular}{|c|c|c|c|c|}
\hline & $\begin{array}{c}\text { Asthmatics with } F E V_{1} \text { long- } \\
\text { term change } \leq 5 \% \\
\text { (14 subjects) }\end{array}$ & $\begin{array}{c}\text { Asthmatics with } F E V_{1} \text { long-term } \\
\text { change between } 5 \text { and } 15 \% \\
\text { (19 subjects) }\end{array}$ & $\begin{array}{c}\text { Asthmatics with } \mathrm{FEV}_{1} \\
\text { long-term change }>15 \% \\
(13 \text { subjects })\end{array}$ & $\mathbf{p}$ \\
\hline $\begin{array}{l}\Delta \mathrm{FEV}(\mathrm{ml} / \mathrm{year}) \\
\text { between the highest predicted and the latest } \\
\text { values }\end{array}$ & $-20.6 \pm 40.2$ & $31.3 \pm 9.7$ & $33.12 \pm 12.7$ & 0.04 \\
\hline $\begin{array}{l}\text { Time between the highest predicted and the } \\
\text { latest measurements (years) }\end{array}$ & $29 \pm 10$ & $26.84 \pm 9.25$ & $24.85 \pm 17.35$ & 0.1 \\
\hline $\begin{array}{l}\text { Physiological } \triangle \mathrm{FEV}_{1}(\mathrm{ml} / \mathrm{year}) \text { (between the } \\
\text { highest predicted and the latest predicted } \\
\text { measurements) }\end{array}$ & $-21.2 \pm 4.2$ & $-21.51 \pm 3.34$ & $-22.76 \pm 5$ & 0.3 \\
\hline $\begin{array}{l}\text { Physiological } \triangle \mathrm{FEV}_{1}(\%) \\
\text { between the highest predicted and the latest } \\
\text { predicted measurements) }\end{array}$ & $-15.17 \pm 12.5$ & $-13.55 \pm 10.7$ & $-17.1 \pm 7.26$ & 0.09 \\
\hline
\end{tabular}

See materials and methods for formulas used to calculate the various $\mathrm{FEV}_{1}$ declines. Comparisons were made by using ANOVA test.

Thirteen patients (28.3\%; mean age: 50.1 10.1 ) highlighted a significant $\mathrm{FEV}_{1}$ decline higher than $15 \%$ in comparison to an older $\mathrm{FEV}_{1}$ (Fig. (1A)), even though their latest $\mathrm{FEV}_{1}$ and $\mathrm{FEV}_{1} / \mathrm{VC}$ were higher than the GLI2012 low limit of normality and their z-score $>-1.5$ (see Table 1 for mean values). The prevalence of subjects with long term $\mathrm{FEV}_{1}$ decrease $<5 \%$ were 14 (30.4\%; mean age: $\left.46.85 \pm 17\right)$, whereas those with $\mathrm{FEV}_{1} 5-15 \%$ change resulted to be 19 (41.3\%; mean age: 48.6 \pm 8.9 ) (Fig. (1A)). The prevalence of subjects with a decrease $<30,30-60$ and $>60 \mathrm{ml} / \mathrm{year}$, calculated by the formula $\left[\left(\mathrm{FEV}_{1 \text { previous }}-\mathrm{FEV}_{1 \text { latest }}\right) /\right.$ years], was 39,37 and $24 \%$ respectively (Fig. (1B)). When the highest predicted value was used as reference point, and the reduction was corrected by subtracting the physiological

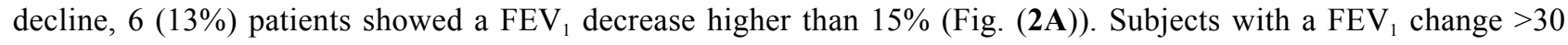
$\mathrm{ml} /$ year, compared to the highest predicted values $\left(\left[\left(\mathrm{FEV}_{1 \text { highest predicted }}-\mathrm{FEV}_{1 \text { latest }}\right) /\right.\right.$ years $\left.]\right)$, were 17 (36.9\%) (Fig. (2B)).

A

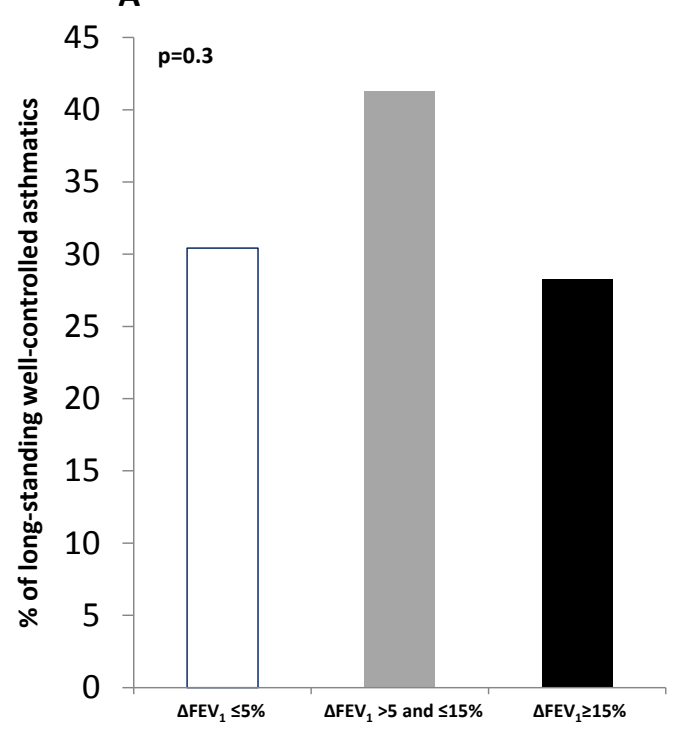

B

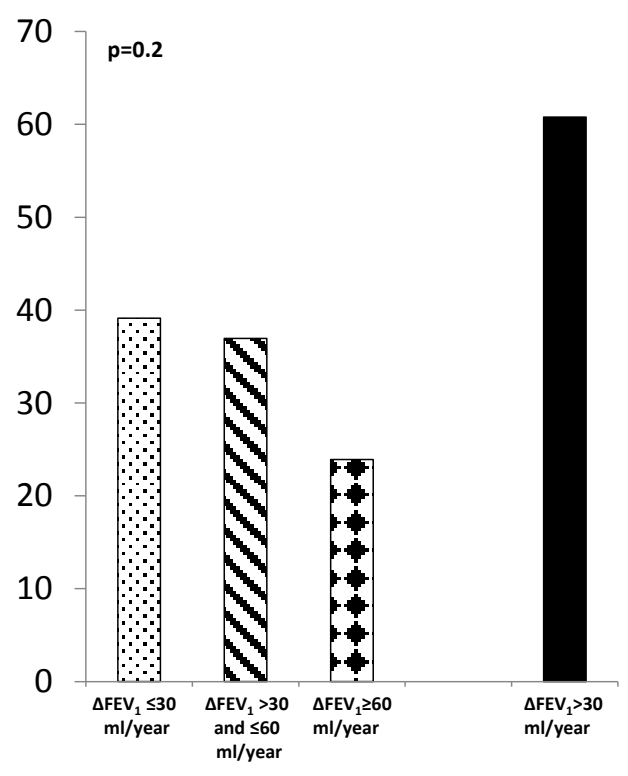

Fig. (1). Prevalence of long-standing asthmatics with different $\mathrm{FEV}_{1}$ declines calculated by subtracting the latest measurement from a previous one. A: $\mathrm{FEV}_{1}$ decline expressed in percentage; B: FEV1 decline expressed in $\mathrm{ml} /$ year.

See materials and methods for formulas used to calculate the various FEV1 declines. Comparisons were made by using $\chi^{2}$ test. 

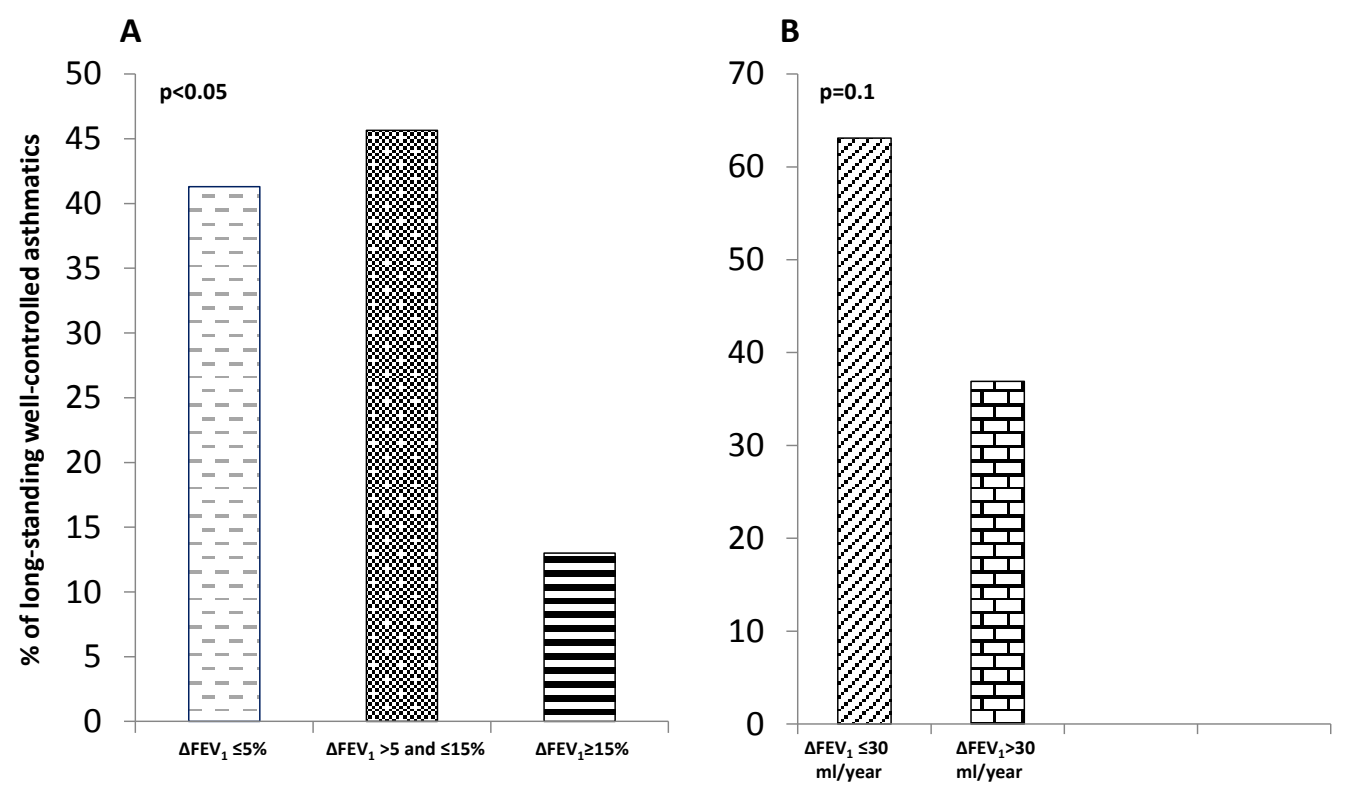

Fig. (2). Prevalence of long-standing asthmatics with different $\mathrm{FEV}_{1}$ declines calculated by subtracting the latest measurements from the highest predicted value (measured at 21 years for females and 23 years for males), used as reference point. A: FEV decline expressed in percentage (corrected by subtracting the physiological $\mathrm{FEV}_{1}$ decline); $\mathbf{B}: \mathrm{FEV}_{1}$ decline expressed in ml/year.

See materials and methods for formulas used to calculate the various FEV1 declines. Comparisons were made by using $\chi^{2}$ test.

\section{DISCUSSION}

As highlighted by this study, approximately $28 \%$ of well-controlled asthmatics showed a significant $\mathrm{FEV}_{1}$ decline $(>15 \%)$ when compared to an approximately 8-year earlier measurement, despite their latest $\mathrm{FEV}_{1}$ and $\mathrm{FEV}_{1} / \mathrm{VC}$ (and zscores) were normal, greater than the LLN (according to GLI2012). The percentage of subjects with "normal" lung function, but with a significant $\mathrm{FEV}_{1}$ decline rose to $60 \%$ when a cut-off $>30 \mathrm{ml} /$ year was used to define a pathological limit of long-term $\mathrm{FEV}_{1}$ change $[2,3]$. Therefore, this accelerated lung function deterioration might regard a remarkable number of subjects with "normal" pulmonary function that would remain undiagnosed without a comparison with a previous spirometry. Identification of "declining" asthmatics may indicate that they are either steroid-resistant or inadequately treated because they are either under-perceivers or poorly adherent to therapy. They may also be unable to use devices properly or have an inadequate lifestyle. We should also consider greater noxious environmental exposure (allergens, smoking habits, working exposure, air pollution, etc.) and other associated diseases (rhinitis, gastroesophageal reflux, etc.) that may influence lung function deterioration [3].

The three different $\mathrm{FEV}_{1}$ decline levels identified in this population of treated long-standing asthmatics are perfectly in line with what was found in another study conducted on asthmatics assessed after 5, 10 and 15 years [9], that showed a $\mathrm{FEV}_{1}$ decline of $<60 \mathrm{ml}$ and $>60 \mathrm{ml}$ in $35-60 \%$ and $20-35 \%$ of patients respectively, whereas no change were observed in $10-25 \%$ of them. These different severities of $\mathrm{FEV}_{1}$ decline may identify distinct asthma phenotypes with dissimilar responses to anti-inflammatory therapies. In fact, different levels of lung function decline may be simply due to diverse inflammatory patterns characterizing asthmatics: Th2, Th2/17 and Th17. These phenotypes may have no/scarce, moderate and severe $\mathrm{FEV}_{1}$ decline respectively, that may be associated with an inverse response to antiinflammatory treatment $[10,11]$. Therefore, it is also likely that a different severity of decline (mild-moderate or severe), in well treated asthmatics, may be a marker that would allow identifying 'responsive' and 'non-responsive' subjects to treatment and therefore those with more severe asthma.

As already stated, according to this study, a latest measured value within normal range of references $(>\operatorname{LLN})$ may 
lead us to an incorrect evaluation of long-standing asthmatics. In fact, such "normal" values might lead to an underestimation of bronchial obstruction and therefore asthma severity, if we do not make a comparison with an at least 5-year-old spirometry. This apparent normality is due to the annual physiological reduction of normal range references (including the ones proposed by GLI2012) [6 - 8] that may hide a significant lung function decrease in time. In fact, normal predicted values and low limit of normal (LLN) increase until the age of 21-23 and then decrease in the following years, even though height (used to calculate predicted values) remains unchanged [6 - 8]. This progressive reference value reduction with age may conceal a significant functional deterioration due to asthma airway remodeling. Besides, low limit of normal (LLN) (also decreasing with age) may be lower than the predicted value of approximately $20 \%$ or more $(700-800 \mathrm{ml})$. Such a large normality range may falsely lead to consider a low (but higher than LLN) $\mathrm{FEV}_{1}$ measured value as normal, in case we have no past functional reference measurements. Consequently, percentage values calculated from the predicted and their z scores, obtained in two measurements effected at a distance of years, may be approximately similar and higher than LLN values, which consequently result normal. Changes in predicted values may be excessive for some asthmatics over the course of time: lung function was and remained normal despite its significant decline in time. Therefore, asthma-induced lung function decline may be unchecked if it is higher than the physiological reduction of predicted lower limit of normality. This may regard especially younger subjects showing high lung function values at asthma onset, much higher than normal references, and that during the following years are characterized by a moderate asthma $\mathrm{FEV}_{1}$ decline (between 30-80 ml/year). Their predicted and LLN values may be unable to detect these significant variations occurring during a long period of time, as it has been observed in some patients in this study. An early decrease of normal predicted and LLN values, starting after 21-23 years of age, might explain such erroneous assessment. In our opinion, reference values should begin to decrease later. Likely, such values should reach their peak at the above said age (due to growth). Later, we suppose they should remain constant in time (at least in some subjects to be identified) or decrease more slowly until the age of 35 (or later) and then begin to decrease physiologically. In fact, observing the distribution of healthy subjects with normal/high values of pulmonary function, we can see that this remains unchanged in a remarkable number of 20-40 age-bracket individuals [7]. Therefore, not all subjects seem to show a physiological lung function decline during youth. Even asthmatics may not report any lung function deterioration. In fact, approximately $30 \%$ of our asthmatics showed that their lung function remains unchanged in time, when compared to older measurement. Furthermore, several factors may influence loss in pulmonary function which is not evaluated in healthy subjects taken into consideration for population lung function references. For example, air pollution, workplace exposure, fat diet and obesity can affect lung function decline [3]. In addition, the presence of most respiratory diseases was excluded only by a questionnaire during the recruitment of reference population samples. In fact, also other respiratory diseases (COPD, interstitial diseases, and occupational exposure damages) can show lung function deterioration in time.

Often, when we manage long-standing asthmatics, we might not have an old spirometry and therefore we might not have a reference point to calculate $\mathrm{FEV}_{1}$ decline. The "highest predicted $\mathrm{FEV}_{1}$ value" (measured at 21 years for females

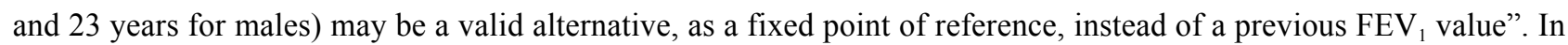
fact, using this reference point, reduced by subtracting the physiological change in time, (i.e. $\left[\left(\mathrm{FEV}_{1 \text { highest predicted }}-\mathrm{FEV}{ }_{1}\right.\right.$ latest $\left.)-\left(\mathrm{FEV}_{1 \text { highest predicted }}-\mathrm{FEV}_{1 \text { latest predicted }}\right) / \mathrm{FEV}_{1 \text { highest predicted }}{ }^{*} 100\right)$ we found that $6(13 \%)$ patients showed a significant $\mathrm{FEV}_{1}$ decline (higher than 15\%) showing that these patients were really affected by airway obstruction. Subjects with an accelerated lung function decline became 17 (36.9\%) in case we used a $\mathrm{FEV}_{1}$ change in time $>30 \mathrm{ml} /$ year (compared to the highest predicted) as a significant long-term decrease cut-off. If we had these long-term changes available on each spirometry (automatically calculated), we could have reference values that might allow considering asthma airway remodeling on lung function. A fixed reference point could therefore permit to calculate $\mathrm{FEV}_{1}$ decline (to be shown in spirometry reports) which may improve asthma monitoring and give spirometry a different role. Fixed "highest" values, taken as reference values, may give a "dynamic" vision in time, whereas "FEV ${ }_{1}$ predicted value", reducing with age, gives only a "static" asthma evaluation only at a specific moment in time.

We retain that $\mathrm{FEV}_{1}$ decline should always be considered because it allows evaluating the real impact of asthma on long-standing asthmatics more correctly, otherwise they would be erroneously considered as well controlled. This evaluation of pulmonary function decline is currently performed for workers with the purpose of screening possible pulmonary damages caused by occupational exposure (asbestos, coke oven emissions, cadmium, cotton dust, benzene, formaldehyde etc) [5]. Since asthma is due to allergen-exposure causing inflammation-induced airway remodeling [1, 3], and thus lung function decline, a long-term monitoring should be also considered in asthma, in order to establish treatment efficacy, despite a good symptom control [3]. Therefore, as already stated, despite a good symptom control, 
identifying declining asthmatics may allow us to make some treatment adjustments, i.e. improving adherence and /or increasing inhaled corticosteroid doses when they are particularly low. In fact, long-term clinical trials have shown that inhaled corticosteroids can slow down lung function decline in asthma [12 - 16]. In particular, an early treatment with inhaled corticosteroids can reduce $\mathrm{FEV}_{1}$ loss more significantly [12, 16]. Furthermore, it may be advisable to reduce harmful environmental exposure and improve lifestyle in order to contrast lung function deterioration in time [3]. In fact, some studies have shown that weight reduction may be beneficial on asthma outcomes and above on all lung function decline $[17,18]$.

However, it must be underlined that, when evaluating changes between two measurements (at a distance of several years), variability of $\mathrm{FEV}_{1}$ in repeated measurements should be considered [2 - 4]. Therefore, it is advisable to calculate $\mathrm{FEV}_{1}$ decline considering the $\mathrm{FEV}_{1}$ values obtained after using a bronchodilator. Furthermore, lung function decline evaluation should be supported by some intermediate, progressively decreasing measurements (between the first and the last spirometries) in order to confirm deterioration in time.

\section{CONCLUSION}

In approximately $28 \%$ of asymptomatic long-standing asthmatics, if their latest lung functional value within reference normal range is compared with one at least 5 years older, we can see a significant pulmonary function decline $(>15 \%)$. The apparent "normality" of the latest measurement may lead us to an underestimation of asthma severity in these asthmatics. This bias is due to a physiological reduction of reference values for spirometry with age that can hide an asthma-induced lung function decline (remodeling). The highest predicted value obtained at the age of 21 years for

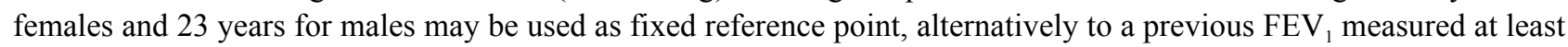
five years earlier, to calculate $\mathrm{FEV}_{1}$ decline. In subjects with "normal" lung function, availability of the $\mathrm{FEV}_{1}$ decline measurement on the report of spirometry, either from previous or from the highest predicted values, may allow us to see how severe their asthma is despite the absence of symptoms and, consequently, lead to a better disease management. Obviously, further studies should be necessary to validate this approach to asthma.

\section{CONFLICT OF INTEREST}

The author declares that they have no conflicts of interest in relation to this article.

\section{ACKNOWLEDGEMENTS}

Declared none.

\section{DISCLOSURE}

Dr. B. Sposato, as the main researcher, is responsible for the conception and design of the article as well as interpretation, analysis and writing.

\section{REFERENCES}

[1] Global Strategy for Asthma Management and Prevention: Global Initiative for Asthma (GINA) 2014. Available from: http://www.ginasthma.org/ [Accessed: Aug 12, 2016]2014.

[2] Pellegrino R, Viegi G, Brusasco V, et al. Interpretative strategies for lung function tests. Eur Respir J 2005; 26 (5): $948-68$. [http://dx.doi.org/10.1183/09031936.05.00035205] [PMID: 16264058]

[3] Sposato B. Could $\mathrm{FEV}_{1}$ decline have a role in daily clinical practice for asthma monitoring? Curr Med Res Opin 2013; 29(10): 1371-81. [http://dx.doi.org/10.1185/03007995.2013.821057] [PMID: 23815105]

[4] Levy ML, Quanjer PH, Booker R, Cooper BG, Holmes S, Small I. Diagnostic spirometry in primary care: Proposed standards for general practice compliant with American Thoracic Society and European Respiratory Society recommendations: a General Practice Airways Group (GPIAG)1 document, in association with the Association for Respiratory Technology \& Physiology (ARTP) 2 and Education for Health3 1 www.gpiag.org 2 www.artp.org 3 www.educationforhealth.org.uk. Prim Care Respir J 2009; 18(3): 130-47. [http://dx.doi.org/10.4104/pcrj.2009.00054] [PMID: 19684995]

[5] Townsend MC. Evaluating pulmonary function change over time in the occupational setting. J Occup Environ Med 2005; 47(12): 1307-16. [http://dx.doi.org/10.1097/01.jom.0000188332.10217.4b] [PMID: 16340713]

[6] Quanjer PH, Brazzale DJ, Boros PW, Pretto JJ. Implications of adopting the global lungs initiative 2012 all-age reference equations for spirometry. Eur Respir J 2013; 42(4): 1046-54.

[http://dx.doi.org/10.1183/09031936.00195512] [PMID: 23520323] 
[7] Global Lung Function Initiative. Available from: http://www.lungfunction.org [Accessed: Feb 02, 2014$] 2014$.

[8] Quanjer PH, Stanojevic S, Cole TJ, et al. ERS global lung function initiative: multi-ethnic reference values for spirometry for the 3-95-yr age range: the global lung function 2012 equations. Eur Respir J 2012; 40: 1324-43. [http://dx.doi.org/10.1183/09031936.00080312] [PMID: 22743675]

[9] Connolly CK, Prescott RJ. The Darlington and Northallerton long term asthma study: pulmonary function. BMC Pulm Med 2005; 5: 2. [http://dx.doi.org/10.1186/1471-2466-5-2] [PMID: 15683540]

[10] Wenzel SE. Asthma phenotypes: the evolution from clinical to molecular approaches. Nat Med 2012; $18(5)$ : $716-25$. [http://dx.doi.org/10.1038/nm.2678] [PMID: 22561835]

[11] Cosmi L, Liotta F, Maggi E, Romagnani S, Annunziato F. Th17 cells: new players in asthma pathogenesis. Allergy 2011; 66(8): 989-98. [http://dx.doi.org/10.1111/j.1398-9995.2011.02576.x] [PMID: 21375540]

[12] Haahtela T. Lung function decline in asthma and early intervention with inhaled corticosteroids. Chest 2006; 129(6): 1405-6. [http://dx.doi.org/10.1378/chest.129.6.1405] [PMID: 16778255]

[13] Busse WW, Pedersen S, Pauwels RA, et al. The inhaled steroid treatment as regular therapy in early asthma (START) study 5-year follow-up: effectiveness of early intervention with budesonide in mild persistent asthma. J Allergy Clin Immunol 2008; $121(5)$ : $1167-74$. [http://dx.doi.org/10.1016/j.jaci.2008.02.029] [PMID: 18405951]

[14] Dompeling E, van Schayck CP, van Grunsven PM, et al. Slowing the deterioration of asthma and chronic obstructive pulmonary disease observed during bronchodilator therapy by adding inhaled corticosteroids. A 4-year prospective study. Ann Intern Med 1993; 118(10): 770-8. [http://dx.doi.org/10.7326/0003-4819-118-10-199305150-00003] [PMID: 8470851]

[15] OByrne PM, Lamm CJ, Busse WW, Tan WC, Pedersen S. The effects of inhaled budesonide on lung function in smokers and nonsmokers with mild persistent asthma. Chest 2009; 136(6): 1514-20. [http://dx.doi.org/10.1378/chest.09-1049] [PMID: 19710291]

[16] OByrne PM, Pedersen S, Busse WW, et al. Effects of early intervention with inhaled budesonide on lung function in newly diagnosed asthma. Chest 2006; 129(6): 1478-85. [http://dx.doi.org/10.1378/chest.129.6.1478] [PMID: 16778264]

[17] Marcon A, Corsico A, Cazzoletti L, et al. Body mass index, weight gain, and other determinants of lung function decline in adult asthma. J Allergy Clin Immunol 2009; 123(5): 1069-1074, 1074.e1-1074.e4. [http://dx.doi.org/10.1016/j.jaci.2009.01.040] [PMID: 19321196]

[18] Moreira A, Bonini M, Garcia-Larsen V, et al. Weight loss interventions in asthma: EAACI evidence-based clinical practice guideline (part I). Allergy 2013; 68(4): 425-39.

[http://dx.doi.org/10.1111/all.12106] [PMID: 23452010]

(C) Bruno Sposato; Licensee Bentham Open.

This is an open access article licensed under the terms of the Creative Commons Attribution-Non-Commercial 4.0 International Public License (CC BY-NC 4.0) (https://creativecommons.org/licenses/by-nc/4.0/legalcode), which permits unrestricted, non-commercial use, distribution and reproduction in any medium, provided the work is properly cited. 